\title{
EFEKTIFITAS MAHSRABIYA SEBAGAI PEMBATAS VISUAL (HIJAB) GENDER: SEBUAH EKSPERIMEN MODEL 3D
}

\author{
Said Mahathir
}

Program Studi Arsitektur, Fakultas Sains dan Teknologi, UIN Ar-Raniry, Banda Aceh saidmahathir@gmail.com

\begin{abstract}
Abstrak
Dalam studi yang dilakukan sebelumnya, Mashrabiya (kisi-kisi kayu) dianggap mampu memisahkan zona gender (santriwan-santriwati) pada sebuah perpustakaan pesantren di Kota Langsa, Aceh.Karena penelitian tersebut terbatas pada ekperimen skalatis (1:10) maka hasil yang didapatkan berpotensi bias jika diaplikasikan pada skala sebenarnya (1:1). Oleh karena itu, perlu dilakukan penelitian lanjutan untuk meminimalisir bias dan membuktikan keefektifan Mashrabiya sebagai panel segregasi pada skala manusia. Penggunaan metode eksperimen yang sama seperti pada penelitiansebelumnya terhadap objek skala 1:1 ini akan membutuhkan banyak biaya dan tenaga dalam membangun ruang uji dan pola Mashrabiya-nya. Maka dari itu, penggunakan model 3D merupakan preliminary eksperimen dan analisis yang bertujuan untuk mendapatkan data serta memperkecil jumlah variabel bebas seperti, jumlah lubang, ukuran lubang, luasan baluster, dan, ketebalan panel Mashrabiyassebagai data teknis utama untuk melubangi panel secara manual (handmade) pada penelitian berikutnya.Untuk mempermudah kontrol variabel dan mendapatkan data kuantitif yang presisi dari setiap transformasi modelnya maka eksperimen ini menggunakan perangkat lunak Rhinoceros dengan plug-in Grasshopper untuk membuat algoritma panel Mashrabiya.Hasilnya, dari 20 model 3D Mashrabiyayang disimulasikan hanya empat panel memenuhi syarat (Perforation Ratio) PR, (hole area) HA dan (baluster area) BA sehingga efektif bekerja sebagai pemabatas visual zona gender dan juga sangat adaptif terhadap akses keluar masuk cahaya dan udara. Dari sisi konstruksi pun panel-panel mahsrabiya yang terpilih ini masih sangat mungkin diproduksi secara manual (handmade).
\end{abstract}

Kata-kata Kunci:Hijab (Pembatas Visual), Mashrabiya (kisi-kisi kayu), Eksperimen model3D, Algoritma.

\section{EFFCTIVENESS OF MASHRABIYA AS A VISUAL INTERFERENCE (HIJAB) BETWEEN GENDERS: A 3D MODEL EKSPERIMENT}

\begin{abstract}
In previous research, Mashrabiya (wooden lattice) have been concluded for being able to separate gender zone (male and female student) in a library of an Islamic boarding school (Pesantren) in Kota Langsa, Aceh. Since the experiment was limited on a scale model (1:10), the obtained result potentially lead to some biases if it is applied on a human scale model (1:1). Therefore, further research to minimize the biases and prove the effectiveness of Mashrabiya as gender segregator panel is needed. Applying the same experimental method as in the previous research on human scale model will cost a significant amount of experiment materials and labors in order to build a sample room and the patterns of Mashrabiya. Therefore, 3 dimensional (3D) model eksperimental method and analysis is a solution aimed at obtaining data, separating and minimizing the number of independent variable such as, number of holes, size of holes, width of baluster area,
\end{abstract}


and thickness of the panel; those technical data will be used in hollowing out the panel (manually) in the next research. To ease the control of variables and to obtain a precise quantitative data in every transformed 3D model, then this experiment utilizes Rhinoceros software with Grasshopper plug-in to produce the algorithm of Mashrabiya panels.The result conclude that from 20 of $3 D$ models of Mashrabiya panels only four panels that qualified in term of (Perforation Ratio) PR, (hole area) HA and (baluster area) BA so then will work effectively as a visual interference panel between gender zones as well as very adaptive on natural lighting and air flow accessibility. In term of the Mashrabiya production, these chosen panels are still can be produced manually (handmade).

Keywords: Hijab (Visual Interference), Mashrabiya (wooden lattice), $3 D$ model eksperiment, Algorithm.

\section{Pendahuluan}

Provinsi Aceh merupakan satu-satunya provinsi di Indonesia yang secara resmi telah menerapkan syariat Islam diberbagai sendi kehidupan masyarakatnya termasuk pada sektor pendidikan. Ini terlihat pada aturan-aturan syariah yang dituangkan dalam Qanun (Peraturan Daerah)dan diterapkan pada institusi-institusi pendidikan baik formal mupun non-formal. Namun lama sebelum penerapan regulasi ini ke dalam Perda, secara khusus, pesantren (Dayah) telah menerapkan aturan-aturan syariat Islam tersebut; bahkan telah memiliki instrument fisik yang terlihat pada bangunan-bangunan pendidikannya seperti Hijab (pembatas) pada ruangan- ruangan tertentu.

Madrasah Ulumul Quran, Kota Langsa, merupakan salah satu contoh pesantren yang menerapkan aturan pemisahan zona gender pada perpustakaan. Mekanisme pemisahannya adalah berupa jarak $(>1 \mathrm{~m})$ dan partisi (dinding atau rak buku)setinggi $2 \mathrm{~m}$. Hanya saja mekanisme ini kerap menimbulkan masalah sehingga masih mungkin terjadi interaksi visual-verbal antar lawan jenis. Kondisi ini dianggap belum menyelesaikan permasalahan pemisahanzona gender.Hadist Nabi yang diriwayatkan oleh Abdullah bin Abbas ra. "Janganlah seseorang laki-laki berkhalwat dengan seorang wanita kecuali bersama mahramnya” (HR. Bukhari dan Muslim), menjadi dasar ketat peraturan pesantren dalam membatasi interaksi antar lawan jenis kecuali mahramnya. Dalam pengelolaannya, pihak pesantren hanya mampu mengubah manajemen penggunaan perpustakaan tersebut dengan cara seperti; 1) memisahkan ruang koleksi dan ruang baca santriwan dan santriwati, 2) membagi jam atau hari kunjungan perpustakaan berdasarkan gender. Akan tetapi kedua mekanisme pemisahan itu dirasa tidak efektif dalam memisahkan zona gender sehingga dibutuhkan solusi arsitektural guna menjawab permasalahanmetode segregasi zona gender. Berdasarkan studi literatur yang dilakukan,Mashrabiya (kisi-kisi kayu) merupakan panel tradisional timur tengah yang dianggap berpotensi memisahkan kedua zona sehingga perlu dikaji lebih dalam terkait efektifitasnya pada ruangan yang sempit.

Namun demikian, penelitian sebelumnyaterhadap Mashrabiyamemiliki batasan pada skala yang tidak realistis (1:10) sehingga berpotensi bias jika diasumsikan bekerja efektif pada skala 1:1 (skala manusia). Oleh karena itu, perlu dilakukan penelitian lanjutan berskala manusia untuk meminimalisir bias dan membuktikan keefektifan Mashrabiya sebagai media segregasi.Akan tetapi, jikamenerapkan metode penelitian sebelumnya pada skala 1:1 ini, akan membutuhkan banyak material dan tenaga dalam membangun ruang uji dan pola Mashrabiya nya. Maka dari itu, eksperimen model 3D merupakan preliminary eksperimen dan analisis yang bertujuan untuk mendapatkan data serta memperkecil jumlah variabel bebas (pola lubang, ukuran lubang, dll.) Mashrabiya untuk dieksperimentasikan padaruang ujiberskala 1:1. Guna mempermudah kontrol variabel dan mendapatkan data kuantitif yang presisi dari setiap transformasi modelnya maka eksperimen ini menggunakan perangkat lunak Rhinoceros dengan plug-in Grasshopper untuk 
membuat algoritma panel Mashrabiya. Dengan demikian, hanya panel dengan ukuran yang terpilih lah yang dapat dilanjutkan ke tahap penelitian efektifitas Mashrabiya dengan skala 1:1.

Adapun sasaran dari penelitian ini adalah ditemukannya data variabel bebas seperti 1) jumlah lubang, 2) ukuran lubang, 3) luasan baluster, dan, 4) ketebalan panelMashrabiyasebagai data teknis utama untuk melubangi panel secara manual (hand made) pada penelitian berikutnya.Harapannya adalah panel Mashrabiya bekerja efektif sebagai pemisah zona gender dan dapat diaplikasikan pada bangunan-bangunan dengan fungsi dan syarat khusus yang membutuhkannya seperti di daerah Aceh.

\section{Kajian Pustaka}

\section{Sistem Segregasi Zona Gender (Hijab)}

Ada dua sistem segregasi zona gender(hijab)yang telah diaplikasikan pada bangunan perpustakan tersebut.Pertama, (Insivisible boundaries) atau hijab maya, yaitu pembatas kasat mata yang terbantuk olehpsikologis pengguna bangunan dalam mempertahankan zonanya. Sebagai contoh, ketika siswa putra dan putri ditempatkan pada satu ruang terbuka tanpa dibatasi partisi, masing-masing kelompok gendersecara otomatis membagi zona mereka menjadi dua kelompok besar. Ruang kosong diantara kedua kelompok gender tersebut disebut hijab maya yang merupakan upaya siswa dalam memproteksizona individu (personal space zone). Ruang pribadi (Personal space)secara prinsip"merupakan bentuk komunikasi non-verbal" (E.T. Hall, dalam Environmental Psychology, 1984)

\section{Mashrabiya (Anyaman Kayu)}

Jenis pembatas yang kedua adalahhijabfisik, yaitu partisidibuat oleh material atau elemenbangunan yang mampu membatasi pandangan antar zona gender.Pembatas ini dapat diaplikasikan baik secara horizontal (plat lantai) maupun vertikal (partisi). Pada penelitian ini salah satu jenis hijab fisik yang digunakan adalah material pelubangan (Mashrabiya) yang merupakan partisi tradisional masyarakat Timur Tengah.

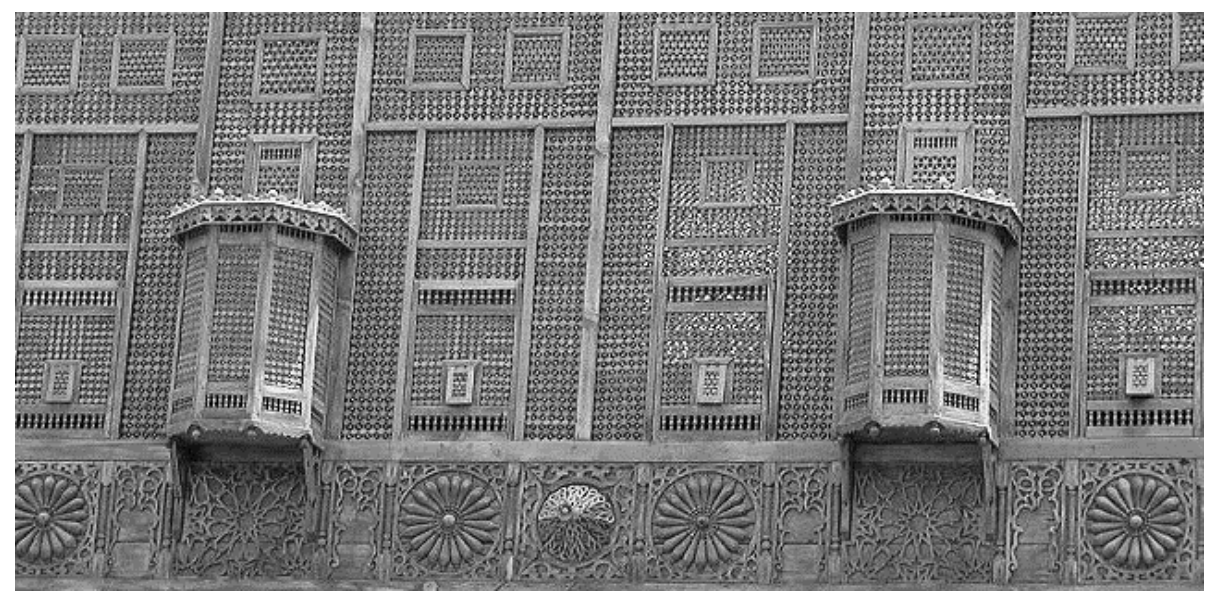

Gambar 1. Mashrabiya

Sumber: https://www.archdaily.com/510226/light-matters-Mashrabiyas-translating-tradition-intodynamic-facades, diakses pada 19 Mei 2019

Mashrabiya adalah salah satu alat segregasi zona gender (hijab) yang berupa partisi ber-pori dan terbuat dari anyaman kayu (Lihat Gambar.1). Jenis panel ini banyak ditemukan pada hunian tradisional masyarakat Timur Tengah.Menurut Kenzari dan Elsheshtawy (2003), "Mashrabiya adalah jendela anyaman kayu yang diintepretasikan sebagai simbol pemisahan dan pengecualian. Ini membuat wanita pada waktu yang bersamaan dapat melihat tetapi tidak terlihat " 
Mahathir dan Prihatmaji (2008) dalam penelitian sebelumnya telah melakukan pengujian terhadap efektifitas material pelubangan (Mashrabiya) dengan skala 1:10.Mereka mensimulasikan reaksi visual manusia terhadap objek dibelakang panel Mashrabiya dan mendokumentasikan nya dalam bentuk video. Adapun yang dianalisa adalah1) variabel bebas; yaitu pola (pattern) pelubangan (ukuran $4 \mathrm{~mm}$ dan $8 \mathrm{~mm}$ ) serta teknik pemasangan material pelubangan, 2) variabel tetap; faktor jarak pandang, sudut pandang dan pencahayaan dalam serta luar ruangan. Di dalamtahapannya, pengujian Mashrabiya dikondisikan pada 2 skenario yaitu sistem uji 1 bilik (ruang) dan 2 bilik dengan pencahayaan yang berbeda (alami dan buatan). Tahapan pertama, sistem uji 1 bilik, menggunakan pencahayaan alami (natural day light) dan buatan (artificaial light) dengan meletakkan sebuah objek di dalam dan luar ruangan yang telah dibatasi oleh Mashrabiya dengan dimensi tertentu kemudian diobservasi dan didokumentasikan dari kedua sisi ruangan. Sama seperti pada tahap sebelumnya, yang membedakan tahap kedua (sistem uji 2 bilik) adalah kedua ruangan mendapatkan intensitas pencahayaan yang sama (Lihat Gambar. 2).

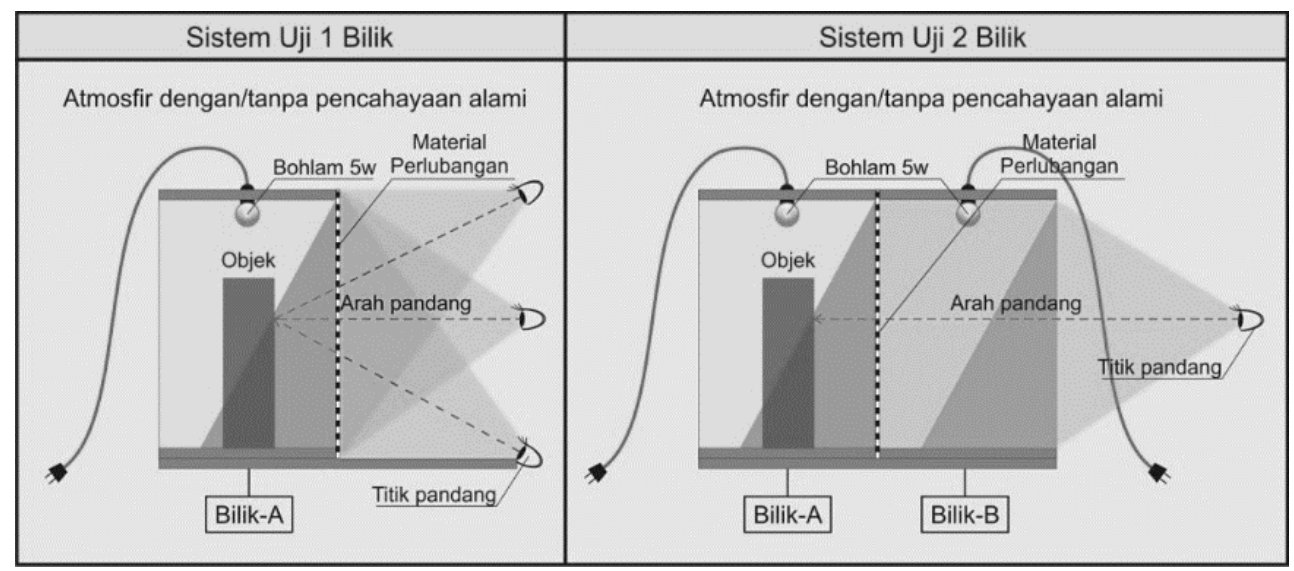

Gambar 2. Skema Eksperimen Panel Mashrabiya Skala 1:10

Sumber: Mahathir dan Prihatmaji, 2008

Berdasarkan penelitian tersebut, kemampuan akses visual dengan sistem uji 1 bilik pada siang hari memperlihatkan hasil yang signifikan sebagai hijab karena subjek diluar ruangan tidak dapat melihat kedalam ruangan, sementara objek didalam ruangan dengan leluasa melihat subjek di luar ruang. Ini disebabkan oleh perbedaan intensitas cahaya dengan perbandingan (50-100 Lux: 500-1000 Lux) antara ruang luar dan ruang dalam. Sedangkan pada malam hari,ketika intensitas ruang luar lebih rendah daripada ruang dalam (eksterior $=0$ Lux dan interior $=500-1000$ Lux.), maka subjek diluar ruangan dapat dengan mudah melihat objek di dalam ruang. Yang menarik adalah ketika Mashrabiya disimulasikan pada sistem uji 2 bilik dengan intensitas cahaya yang sama (500-1000 Lux), Mashrabiya tidak signifikan bekerja karena subjek dan objek dapat melihat satusama lain dengan leluasa.

Sejauh diketahui, di samping faktor intensitas cahaya, pola (pattern), ukuran lubang dan jarak pandang ikut mempengaruhi daya akses visual manusia. Semakin kecil pola (pattern) dan luas baluster (bidang di antara lubang) maka akan semakin tidak terlihat objek di belakang panel. Sebaliknya semakin besar pola lubang dan sempit baluster maka akan semakin jelas objek terlihat. 


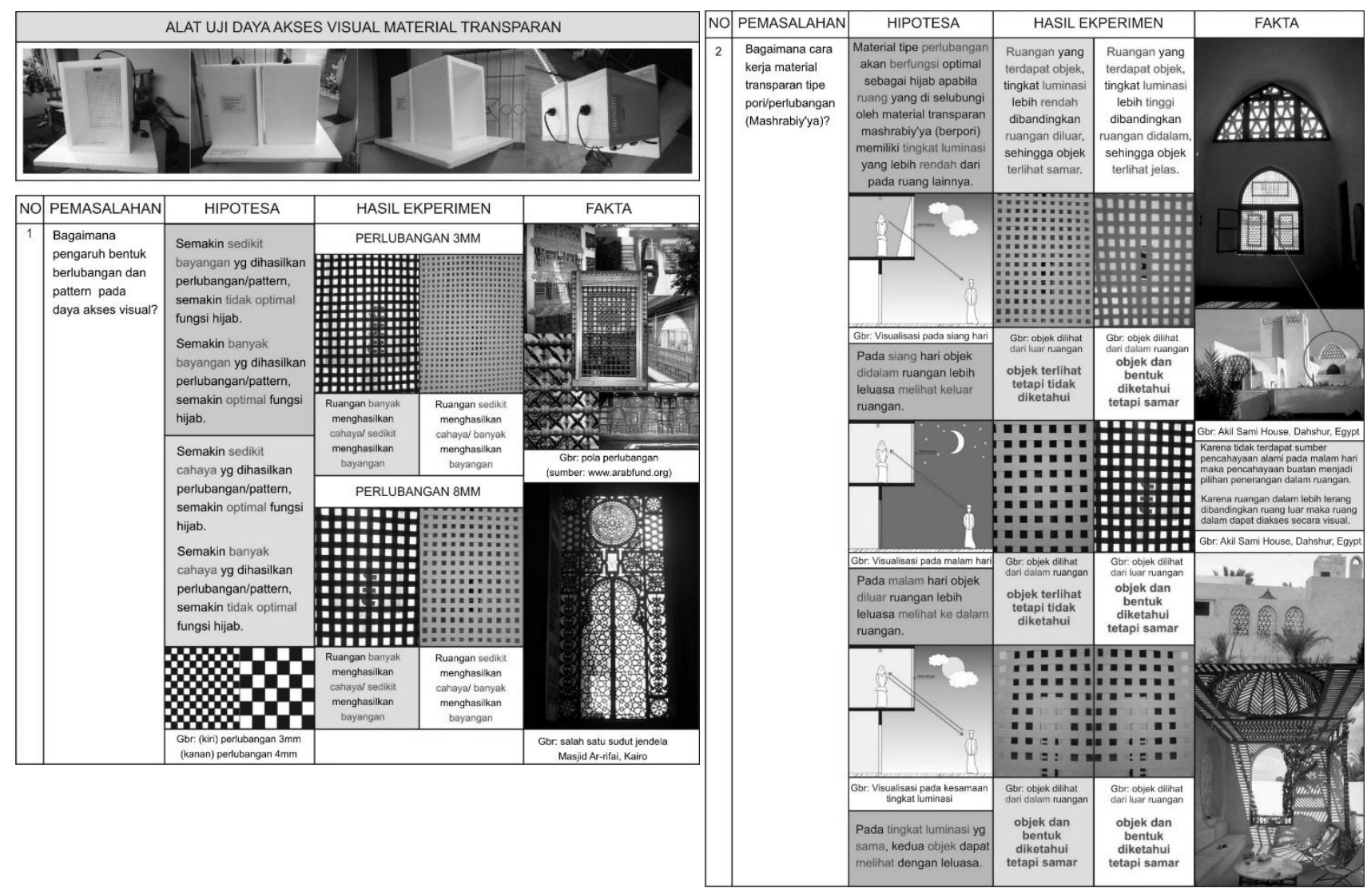

Gambar 3. Kesimpulan Hasil Analisa

Sumber: Mahathir dan Prihatmaji, 2008

\section{Parameter dan Faktor yang Mempengaruhi Mashrabiya}

Menurut Sherif et. Al. (2012) parameter geometri Mashrabiya diklasifikasikan atas: 1) Perforation Ratio (PR) adalah perbandingan antara luasan lubang dan luasan panel keseluruhan, 2) Depth ratio (DR) adalah perbandingan antara ukuran kedalaman lubang dan lebar lubang.Jarak standar antara batang satu dengan batang lainnya menjadi faktor utama agar Mashrabiya dapat berfungsi secara optimal (Gambar.4). Ketebalan panel juga merupakan pokok perhatian, bahkan beberapa Mashrabiya menerapkan panel ganda untuk memaksimalkan fungsi yang diinginkan.

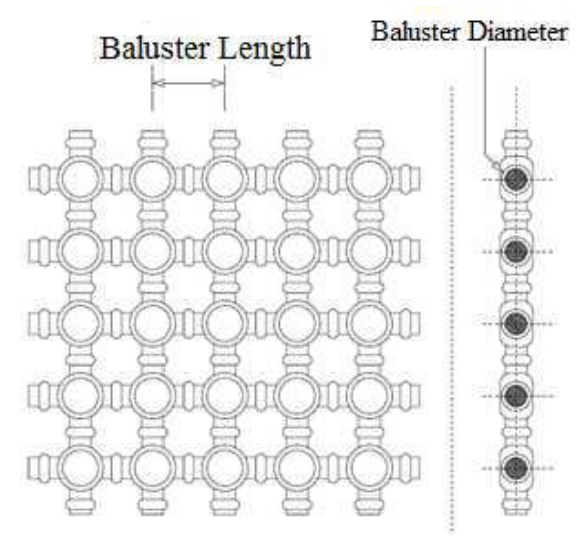

Gambar 4. Jarak dan Ketebalan Mashrabiya Tradisonal Sumber: Samuel, 2011 
Faktor lain yang mempengaruhi kejelasan pandangan terhadap objek adalah; 1) posisi observer (pemandang) yang tegak lurus searah posisi panel, 2) jarak observer dari panel. Sehingga sangat penting untuk mengetahui jarak atau posisi sudut pemasangan Mashrabiya agar tercapai fungsinya sebagai hijab. Jenis pola baluster juga mempengaruhi beberapa aspek efektivitas panel, menurut Fathy (1986), potongan baluster yang berbentuk bola (aerodinamis) memudahkan masuk aliran udara. Disamping itu bentuk bola akan menciptakan gradasi kontras dan bayangan (shade) guna meninimalisir efek pantulan silau (glare) pada bidang yang terpapar cahaya. Disamping itu ukuran baluster akan mempengaruhi lebar atau luasan lubang, yang menurut Samuel (2011), dengan memperkecil ukuran baluster akan mempengharuhi nilai PR (Perforation Ratio) yang secara langsung akan berdampak pada jumlah masuk cahaya ambient (ambient light) dan memudahkan aliran udara.

\section{Metode Penelitian}

Penelitian ini menggunakan metode campuran kuantitatif dan kualitatif dengan pendekatan eksperimen terhadap model 3D Mashrabiya terhadap kemampuan akses visualnya. Tujuannya adalah untuk mencari tingkat efektifitas material perlubanganmelalui analisis hubungan antara dimensi pelubangan (size) denganbidang pembentuknya (baluster) terhadap daya akses visual. Adapun tahapan mekanisme pelaksanaannya meliputi;

\section{Tahap I (Pengumpulan data)}

Pada tahap ini dilakukan kajian teoritis dan studi kasus melalui survey lapangan, jurnal, buku, dan berbagai artikel yang terkait pemanfaatan material pelubangan (Mashrabiya).

\section{Tahap II (Modeling)}

Dalam tahap ini software Rhinoceros versi 5.0 dengan plug-in Grasshopper digunakan untuk membuat algoritma geometri panel Mashrabiya dalam eksperimen ini. Plug-in ini berfungsi sebagai bahasa pemograman visual (Visual Programming Language) yang membentuk model dengan variabel yang terukur sehingga setiap kontrol, modifikasi dan perubahan pada model dapat diukur dan didata dengan presisi secara bertahap.

Sebelum memasuki tahap pemograman, konsep algoritma model perlu dirancang agar memudahkan proses pengumpulan data dan pembuatan model skala 1:1. Pertama, untuk menentukan PR (Perforation Ratio) maka dibutuhkan ketetapan ukuran panel maksimal sebagai modul awal yang selanjutnya dapat digandakan sesuai kebutuhan. Di sini modul awal terkecil yang digunakan adalah 10x10cm (100cm2 ᄀ/100\% PR) dengan alasan i) kemudahan dalam menggandakan objek menjadi kelipatan bilangan yang bulat, ii) kemudahan proses produksi dengan cara manual (handmade).

Selanjutnya menentukan DR (depth ratio) dengan menetapkan ketebalan material yang biasa digunakan sebagai pembentuk Mashrabiya. Pada kasus ini material yang akan digunakan pada tahap eksperiment lanjutan adalah Styrofoam dengan teknik produksi manual. Material tersebut memiliki ketebalan yang beragam, namun untuk kebutuhan panel ukuran yang lazim digunakan adalah 1-3cm, maka dari itu ukuran ketebalan panel yang akan diuji bervariasi mulai 1-3 cm. Setelah ketebalan panel ditentukan, lebar lubang masrabiya tergantung pada lebar atau luasan baluster yang juga ditentukan oleh PR dengan rumus (Luas Baluster $=\sum$ modul panel $-\mathrm{PR}$ ).

Desain lubang masrabiya dibentuk berdasarkan geometri dasar (bujur sangkar), meskipun terdapat beberapa geometri dasar lainnya seperti segitiga, lingkaran, dsb. bujur sangkar dianggap sebagai bentuk dasar yang paling mudah proses pembuatannya secara manual (handmade). Disamping itu, yang lebih penting adalah kesederhana bentuk bujur sangkar dapat dijadikan sebagai standar awal pola geometri Mashrabiya yang pengukuran dimensinya seragam, mudah diukur dan presisi. Sehingga nantinya dapat diaplikasikan pada jenis pola apapun yang standar dimensi lubangnya mengikuti angka minimum dan maksimum dari pola dasar tersebut (bujur sangkar). 
Jumlah lubang per-modul divariasikan dari perkalian dengan bilangan yang sama seperti $(1 \times 1,2 \times 2$ s/d 5x5) sehingga maksimal lubang per-panel adalah 25 lubang.

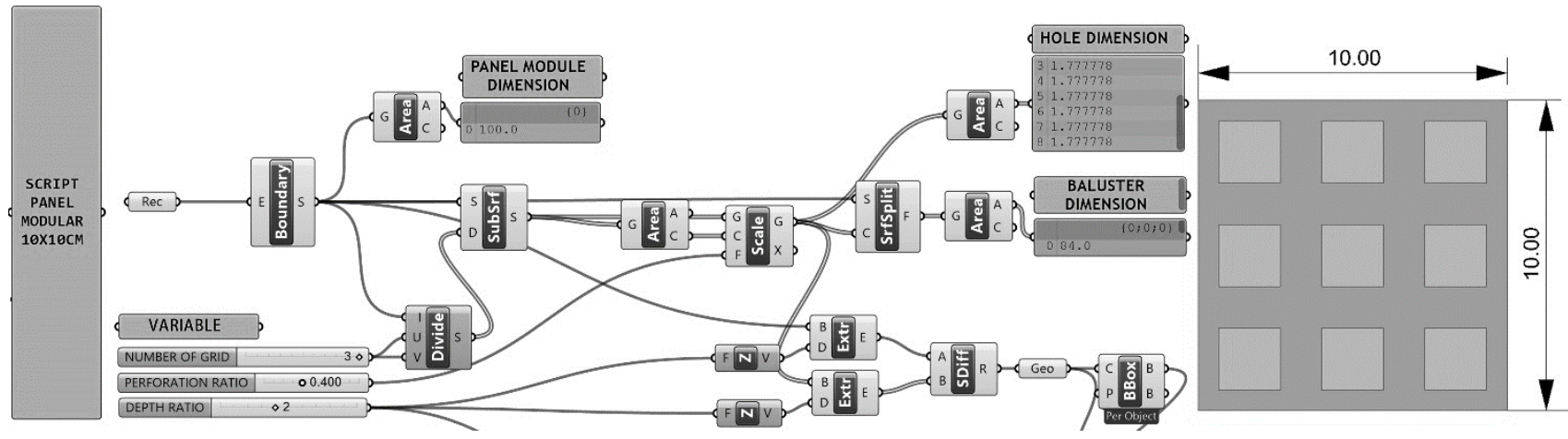

Gambar 5. Script Grasshopper dan Model 3D Mahsrabiya 10x10

Sumber: Analisa, 2018

Script grasshopper diatas merupakan algoritma geometri Mashrabiya dengan modul 10x10cm $\left(100 \mathrm{~cm}^{2}\right)$.Parameter "Rec" adalah objek bujur sangkar yang dibuat langsung pada program Rhinoceros yang selanjutnya dihubungkan dengan komponen "Boundary" (pembatas) luasan total modul masrhabiya. Agar dapat dibagi kedalam beberapa grid, "Boundary" dihubungkan ke komponen "Divide" dan dibagi rata baik secara membujur maupun melintang. Pengatur variabelnya "number slider" diberi nama "Number of Grid" dengan variasi angka 1 (1x1 grid) minimum hingga 5 (5x5 grid) maksimum. Selajutnya area yang telah terbagi dibentuk menjadi bidang independen dengan komponen" "SubSrf" dan masing-masing area diskalakan dengan komponen "scale" untuk menjadi lebih kecil dari ukuran masing-masing permukaan. Karena skala yang digunakan lebih kecil dari objek sebenarnya maka angka pada variabelnya berkisar antara ( $1 \mathrm{~s} / \mathrm{d}$ 0.1), dengan kata lain jika slider nya berada di angka 0.600 artinya 60\% dari ukuran sebenarnya atau $40 \%$ lebih kecil dari ukuran sebenarnya. Persentase skala tersebut bekerja sebagai variabel PR (Perforation Ratio), ini dapat dilihat pada hole dimension (dimensi lubang) yang masing-masing grid berukuran $9 \mathrm{~cm}^{2}$ atau $3 \times 3 \mathrm{~cm}$. "SrfSplit" adalah komponen yang membagi antara luas area yang telah diskalakan dengan luas area sebenarnya yang selanjutnya berfungsi sebagai baluster yang informasi luasanya dapat dilihat pada "Baluster Dimension". Terkakhir dalam tahap ini, untuk mendapatkan DR (depth ratio) maka komponen "Extr" sebagai fungsi extrude objek ke axis Z dihubungkan dengan "Boundary" dan "Scale" sehingga memberi ketebalan bidang yang telah dibagi sebelumnya. Nilai variabel DR (Depth ratio) disesuaikan dengan ketebalan material yang biasa digunakan sebagai material panel konstruksi bangunan konvensional $(1-3 \mathrm{~cm})$

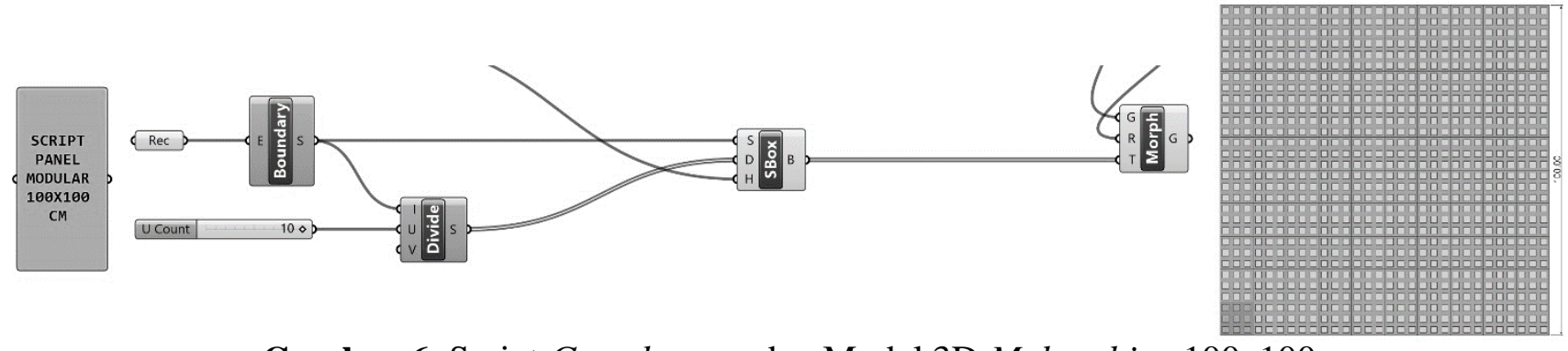

Gambar 6. Script Grasshopper dan Model 3D Mahsrabiya 100x100

Sumber: Analisa, 2018

Setelah modul terkecil dibentuk langkah selanjutnya adalah menyusunnya menjadi modul panel yang lebih besar sesuai dengan skala penggunanya. Untuk memudahkan pada proses produksi 
tangan,ukuran modul panel satuan yang digunakan adalah $100 \times 100 \mathrm{~cm}$. Disamping itu panel dengan dimensi $1 \mathrm{~m}^{2}$ tersebut memudahkan proses pemasangan pada saat konstruksi.
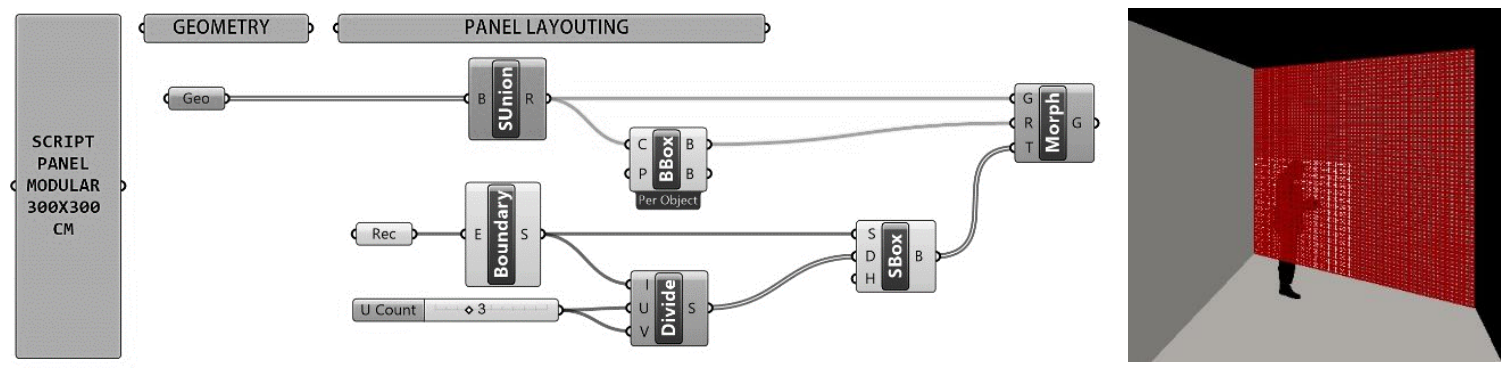

Gambar 7. Script Grasshopper dan Model 3D Mahsrabiya pada ruang 3x3m Sumber: Analisa, 2018

Script modul kecil bertujuan menghubungkan antara bidang modul panel terbesar 100x100cm pada parameter "Rec" sebagai "Boundary"-nya dengan modul panel kecil pada script sebelumnya. "U Count" pada Slider berfungsi menggandakan panel modul 10x10cm kedalam kelipatannya. Angka minimal adalah 1 dan maksimal adalah 10, dengan kata lain jumlah panel kecil didalam panel terbesarnya adalah 100 panel. Terakhir dalam tahap modeling adalah menyusun panel modul $1 \times 1 \mathrm{~m}^{2}$ kedalam sebuah ruang dengan panel yang menghubungakan antara ruang luar (exterior) dan ruang dalam (interior). Tinggi ruangan disesuaikan dengan standar ketinggian ruang perorangan yaitu $3 \mathrm{~m}$ dengan luasan ruangan $9 \mathrm{~m}^{2}$. Disini dibutuhkan script model panel ruang besar $(3 \times 3 \mathrm{~m})$ yang berfungsi menyusun panel satuan terbesar kedalam partisi sebuah ruangan. Parameter "Geo" (Geometry) akan diisi dengan panel Mashrabiya yang ingin di layout ke dalam panel ruangan. Proses "bake" pada script sebelumnya dibutuhkan sebelum diisi ke dalam parameter "Geo". Selanjutnya "Geo" akan dihubungkan dengan komponen "SUnion" guna menyatukan panel tersebut kedalam ukuran ruang yang telah disediakan.

\section{Tahap III (Eksperimentasi)}

Pada tahapan eksperimen terhadap model 3Ddan dianalisa - sintesa guna mempelajari tingkat efektifitas dan hubungannya dengan variabel-variabel yang telah ditentukan. Pada tahapan ini instrumen yang berperan penting adalah model 3 dimensi material pelubangan dengan beberapa jenis ketebalan dan pattern yang terukur, serta pencahayaan buatan yang menyesuaikan dengan keadaan sebenarnya. Eksperimen model 3D dilakukan dengan tujuan menjaring dan membatasi jumlah panel Mashrabiya berskala 1:1 (skala sebenarnya) yang akan diuji pada tahap selanjutnya sehingga memudahkan proses pembuktian. Pembuatan model eksperimen ini menggunakan perangkat lunak (software) Rhinoceros dengan plug-in Grasshopper agar dapat membuat algoritma yang terukur terhadap panel Mashrabiya.

Script model panel Mashrabiya yang telah di "bake" di-render secara bertahap mengikuti urutan variabel yang akan diuji. Sebelum memasuki proses render, terdapat pernyaratan teknis ekperimen yang harus dipenuhi yaitu i) Objek manusia dengan ketinggian rata-rata ras asia $170 \mathrm{~cm}$ menjadi latarbelakang Mashrabiya, ii) jarak objek (manusia) dengan Mashrabiya adalah 1m, iii) cahaya yang digunakan dalam setting $V$-ray disini adalah environment light tanpa membedakan faktor ruang dalam dan ruang luar. Tujuan dari analisis ini adalah untuk menguji transparansi Mashrabiya terhadap objek dibelakangnya.

Script model panel Mashrabiya yang telah di "bake" di-render secara bertahap mengikuti urutan variabel yang akan diuji. Sebelum memasuki proses render, terdapat pernyaratan teknis ekperimen yang harus dipenuhi yaitu i) Objek manusia dengan ketinggian rata-rata ras asia $170 \mathrm{~cm}$ menjadi latarbelakang Mashrabiya, ii) jarak objek (manusia) dengan Mashrabiya adalah 1m, iii) 
cahaya yang digunakan dalam setting $V$-ray disini adalah environment light tanpa membedakan faktor ruang dalam dan ruang luar. Tujuan dari analisis ini adalah untuk menguji transparansi Mashrabiya terhadap objek dibelakangnya.

\section{Hasil dan Pembahasan}

Hasil dari analisis di atas menunjukkan bahwa tidak semua panel bekerja efektif sebagai fungsi pembatas visualHijab. Sebagian panel bersifat terlalu transparan dan sebagian lainnya bersifat masif. Panel dengan Perforation Ratio(PR) di atas $80 \%$ adalah panel yang paling transparan, tidak direkomendasikan sebagai pemisah zona gender. Namun panel dengan rasio hole area (HA) terbesar pada analisis ini $\left(2,56 \mathrm{~cm}^{2} \mathrm{~s} / \mathrm{d} 64 \mathrm{~cm}^{2}\right)$ sangat baik untuk mengatur jumlah cahaya dan aliran udara yang masuk ke dalam ruang. Secara konstruksi ukuran baluster pada panel PR 80 sangat tipis sehingga selain sukar dipotong secara manual panel ini juga terlalu ringkih bila menggunakan material seperti teakwood dan Glass-fibre Reinforced Cement Board (GRC Board).

Disisi lain panel dengan PR terkecil (20\%) terlalu masif sebagai pembatas pandangan yang secara prinsip bekerja seperti panel dinding masif konvensional karena baluster area (BA) yang terlalu besar (BA $84 \mathrm{~cm}^{2}$ ). Dengan kata lain semakin besar baluster area maka semakin kecil hole area. Panel dengan BA yang besar secara signifikan mampu membatasi pandangan namun sangat buruk terhadap akses keluar masuk cahaya dan udara.

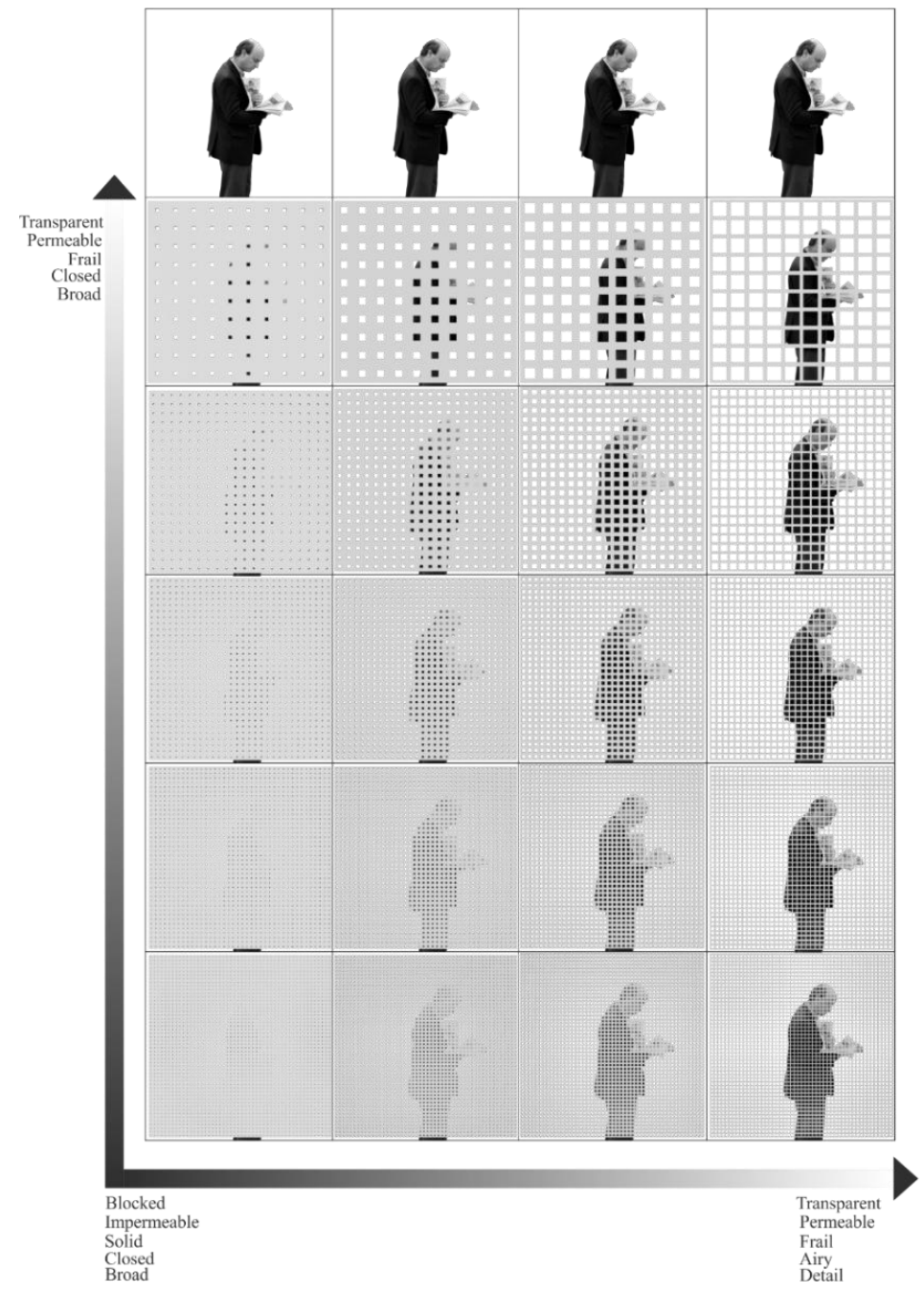

Gambar 8. Perbandingan MashrabiyaPerforation Ratio20\%, 40\%, 60\%, dan $80 \%$ Sumber: Analisa, 2018 
Maka dari itu, berdasarkan data pada empat table di atas, adapun panel yang bekerja optimal sebagai fungsi pembatas visual adalah panel dengan ukuran PR 40-60\% dengan rasio HA antara 1,75 $\mathrm{cm}^{2} \mathrm{~s} / \mathrm{d} 4 \mathrm{~cm}^{2}$, dengan kata lain ukuran dimensi lubang terkecil berkisar antara $1 \mathrm{x} 1 \mathrm{~cm} \mathrm{~s} / \mathrm{d} 2 \times 2 \mathrm{~cm}$. Apabila luasan lubang lebih besar dari pada angka tersebut maka semakin besar pula kemungkinan objek dibelakang panel terlihat, sehingga meminimalisir efektifitas panel sebagai hijab.

Tabel 1.Rekomendasi panel Mashrabiya yang efektif

\begin{tabular}{|c|c|c|c|c|}
\hline$\frac{Z^{2}}{2}$ & 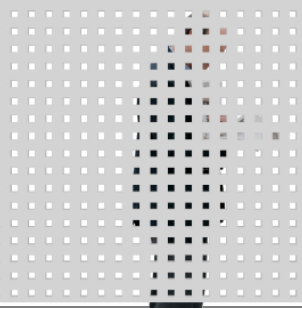 & $\begin{array}{r}0 \\
\vdots \\
\vdots \\
\hdashline\end{array}$ & 無 & 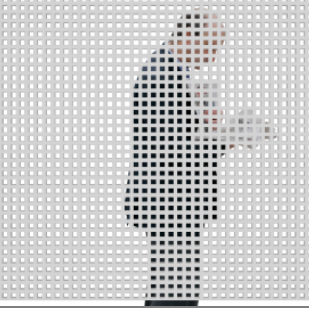 \\
\hline PR & $40 \%$ & $40 \%$ & $60 \%$ & $60 \%$ \\
\hline DR & $2 \mathrm{~cm}$ & $2 \mathrm{~cm}$ & $2 \mathrm{~cm}$ & $2 \mathrm{~cm}$ \\
\hline NH & 4 holes $/ 100 \mathrm{~cm}^{2}$ & 9 hole $/ 100 \mathrm{~cm}^{2}$ & 9 hole $/ 100 \mathrm{~cm}^{2}$ & 12 hole $/ 100 \mathrm{~cm}^{2}$ \\
\hline$\sum \mathbf{N H}$ & 400 holes $/ 1 \mathrm{~m}^{2}$ & 900 holes/ $1 \mathrm{~m}^{2}$ & 900 holes $/ 1 \mathrm{~m}^{2}$ & 1200 holes $/ 1 \mathrm{~m}^{2}$ \\
\hline HA & $\begin{array}{cc}4 \mathrm{~cm}^{2} / & 2 \times 2 \\
\text { hole } & \mathrm{cm}\end{array}$ & $\begin{array}{cc}1,78 \mathrm{~cm}^{2} / & 1,3 \mathrm{x} \\
\text { hole } & 1,3 \\
& \mathrm{~cm}\end{array}$ & $\begin{array}{cc}4 \mathrm{~cm}^{2} / & 2 \times 2 \\
\text { hole } & \mathrm{cm}\end{array}$ & $\begin{array}{cc}2,25 & 1,5 \mathrm{x} \\
\mathrm{cm}^{2} / \text { hole } & 1.5 \\
& \mathrm{~cm}\end{array}$ \\
\hline BA & $84 \mathrm{~cm}^{2} / 100 \mathrm{~cm}^{2}$ & $84 \mathrm{~cm}^{2} / 100 \mathrm{~cm}^{2}$ & $64 \mathrm{~cm}^{2} / 100 \mathrm{~cm}^{2}$ & $64 \mathrm{~cm}^{2} / 100 \mathrm{~cm}^{2}$ \\
\hline
\end{tabular}

Sumber: Analisa, 2018

Keempat panel diatas memenuhi syarat rasio PR, HA dan BA sehingga dalam aplikasinya panel ini selain bekerja optimal sebagai fungsi inisialnya juga sangat adaptif terhadap akses keluar masuk cahaya dan udara. Dari sisi konstruksi pun panel ini masih sangat mungkin diproduksi baik secara manual (crafting) maupun fabrikasi (laser cutting).

\section{Rhinoceros (V-Ray Rendering): Analisis Dan Hasil Visual Ruang Dalam Dan Luar}

Panel Mashrabiya yang di-render adalah panel 3 dimensi yang telah diuji dan dianalisis pada tahap sebelumnya sehingga pada tahap ini dapat dengan optimal untuk dibandingkan antara ruang luar dan ruang dalamnya. Teknis pengujian pada tahap dilakukan melalui pengambilan objek dari sudut kamera dan faktor cahaya ruang dalam dan ruang luar berperan besar sebagai variabel tetap. Sebuah objek gambar manusia dengan jarak $1 \mathrm{~m}$ dari panel diletakkan didalam sebuah ruang dan dibatasi dengan panel Mashrabiya sebesar $9 \mathrm{~m}^{2}$ (3x3m), dan tanpa menggunakan pencahayaan buatan. Selanjutnya 2 titik kamera yang dipasang pada interior dan exterior me-render objek secara bersamaan sesuai dengan variabel yang akan dinilai secara deskriptif

Berdasarkan hasil analisa 3D model yang membandingkan antara ruang luar dan ruang dalam terhadap ke empat jenis panel di atas maka dapat disimpulkan beberapa hal sebagai berikut;

1. Keempat panel tersebut mampu dengan optimal membatasi visual antara ruang luar dan ruang dalam.

2. Intensitas cahaya yang masuk melalui panel Mashrabiya bervariasi tergantung besaran BA dan HA. Semakin besar angka HA maka semakin besar intensitas cahaya yang masuk.

3. Angka BA dan NH berbanding terbalik satu sama lain, semakin kecil BA dan semakin banyak NH, maka cahaya yang dihasilkan semakin banyak pula. Sebaliknya semakin sedikit NH dan semakin besar BA maka cahaya yang masuk semakin sedikit. 
4. Kekontrasan jatuh bayang (cast shadow) dari sebuah objek dipengaruhi oleh intensitas sumber cahayanya, namun pada Mashrabiya dengan NH yang banyak dan BA yang kecil menghilangkan kontras jatuh bayang dengan menciptakan cahaya lembut dari refleksi cahaya pada celah-celah masrhabiya

Tabel 2. Perbandingan Visualisasi dari Ruang dalam dan Ruang Luar

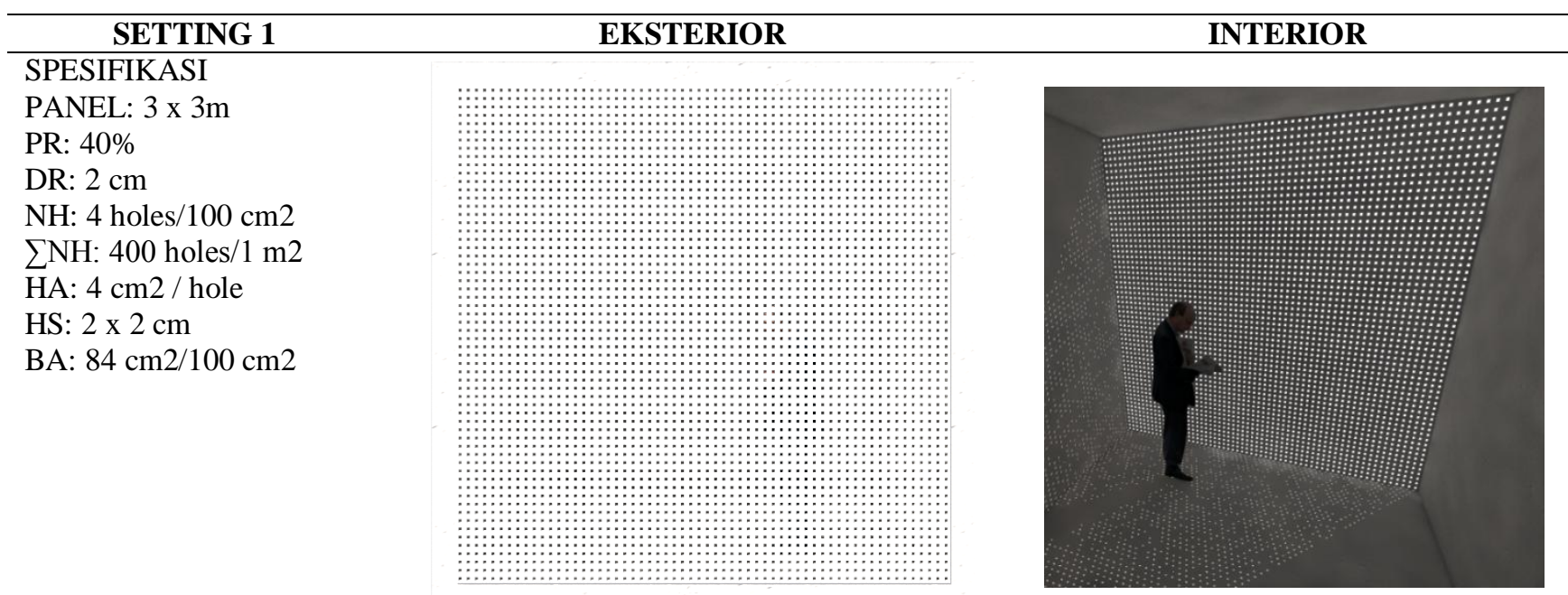

DESKRIPSI SITUASI Bayangan objek di belakang layar terlihat samar sehingga pemandang mengetahui keberadaan user di balik panel tetapi tidak dapat dikenali. Cat yang berwarna putih pada panel menambah efek terang (brightness) pada bidang sehingga semakin memperjelas kontras bayangan dibelakangnya.
Objek di dalam ruangan dapat melihat jelas objek yang terdapat diluar ruangan karena perbedaan cahaya yang kontras. Disamping itu ukuran lubang yang memberikan celah penetrasi cahaya matahari untuk masuk menembus ruangan sehingga memberikan efek iluminasi yang redup dan temaram.

\section{SETTING 2 SPESIFIKASI \\ PANEL: 3 x $3 \mathrm{~m}$ \\ PR: $40 \%$ \\ DR: $2 \mathrm{~cm}$ \\ NH: 9 holes $/ 100 \mathrm{~cm} 2$ \\ $\sum \mathrm{NH}$ : 900 holes/1 m2 \\ HA: $4 \mathrm{~cm} 2$ / hole \\ HS: $1,3 \times 1,3 \mathrm{~cm}$ \\ BA: $84 \mathrm{~cm} 2 / 100 \mathrm{~cm} 2$}

EKSTERIOR

INTERIOR

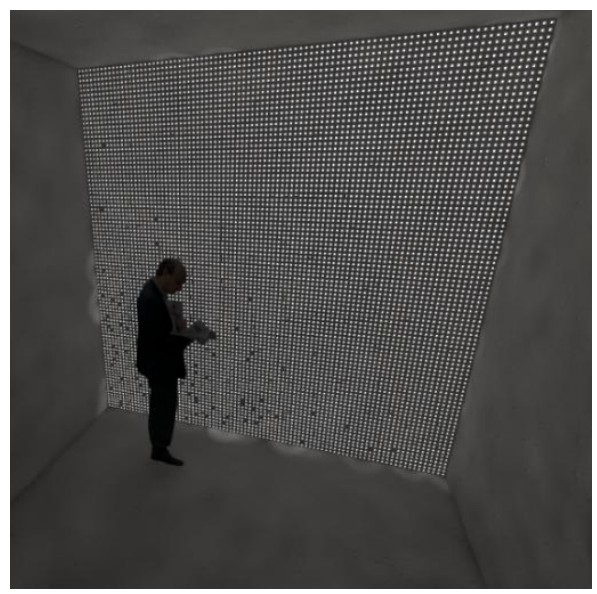

\begin{tabular}{ll}
\hline DESKRIPSI SITUASI & Bayangan objek di belakang layar terlihat \\
& samar. Ukuran lubang yang kecil semakin \\
& mengaburkan objek di belakang layar. Cat \\
& yang berwarna putih pada panel menambah \\
& efek terang (brightness) pada bidang sehingga \\
& semakin memperjelas kontras bayangan \\
& dibelakangnya.
\end{tabular}

Objek di dalam ruangan sedikit terganggu kejelasan melihat objek diluar ruangan karena ukuran lubang yang kecil. Disamping itu ukuran lubang ini sedikit memberikan celah penetrasi cahaya matahari untuk masuk menembus ruangan sehingga memberikan efek gelap. Cahaya buatan berpotensi dipasang dan tidak 


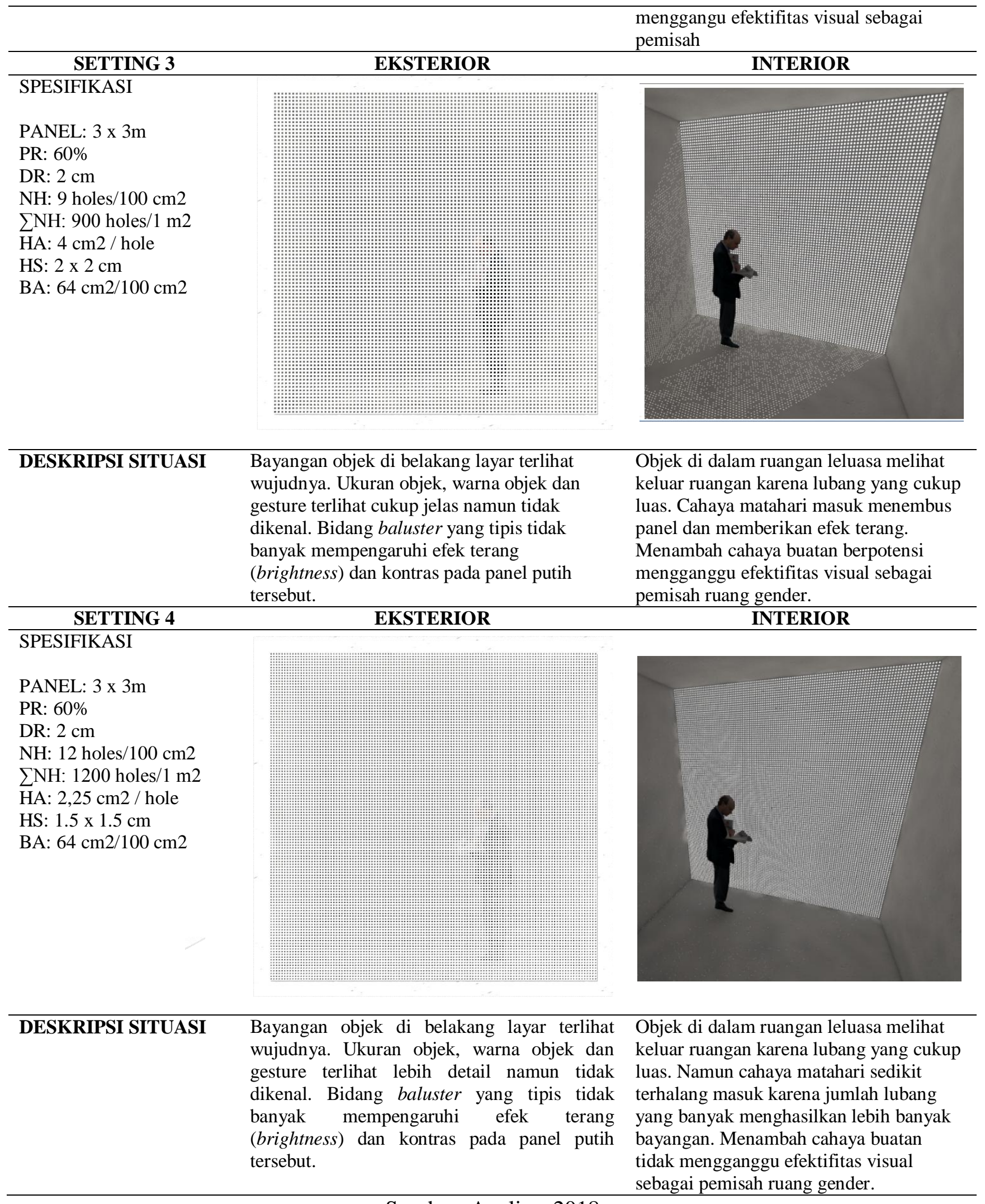

Sumber: Analisa, 2018 


\section{Kesimpulan}

Permisahan zona gender dilakukan dengan menempatkan hijab fisik (pembatas fisik), yang berupa konfigurasi penggunaan dan modifikasi material transparan jenis pelubangan (Mashrabiya) sebagai hijab. Namun, sebelum menggunakan skala sebenarnya (1:1), material hijab ini telah disimulasikan terlebih dahulu dengan menggunakan alat simulasi Hijab. Alat ini berkerja sebagai prototype bagian ruang skalatis yang memperlihatkan reaksi material Mashrabiya terhadap kemampuan visual pengguna bangunan.

Berdasarkan hasil eksperimen digital objek 3 dimensi dengan menggunakan software Rhinoceros dengan plug-in Grasshopper maka diketahui bahwa; hanya empat panel dari spesifikasi yang terpilih memenuhi syarat rasio PR, HA dan BA sehingga dalam aplikasinya panel ini selain bekerja optimal sebagai fungsi inisialnya juga sangat adaptif terhadap akses keluar masuk cahaya dan udara. Dari sisi konstruksi pun dimensi lubang pada panel ini masih sangat mungkin diproduksi secara manual (handmade).

Isu gender penting untuk dipahami dalam koridor yang santun. Melalui sistem material pelubangan(Mashrabiya) diharapkan bisa menjadi bagian dari proses pembentukan karakter muamallah yang lebih beradab. Terlebih lagi di wilayah Aceh yang telah mencanangkan syariat Islam semakin menegaskan urgensi peletakan pola pola kecil dari bagaimana arsitektur melalui integrasi ke- Islaman melihat pria dan wanita dalam sebuah relasi yang mencerdaskan

\section{Daftar Pustaka}

Fisher. Jeffrey D., dkk. 1984. Environmental Psychology, $2^{\text {nd }}$ Edition, New York. CBS Collage Publishing.

Kenzari, Bechir and Yasser Elsheshtawy. 2003. The ambiguous veil: on transparency, mashrabiy'yas and architecture, Journal of Architectural Education

Fathy, H. 1986. Natural Energies and Vernacular Architecture, Mashrabiya(pp. 46-49). Chicago, USA: The University of Chicago Press.

Mahathir, Sayed dan Yulianto P. Prihatmaji. 2008. Efektifitas Material Perlubangan "Mashrabiya" Sebagai Hijab Gender Pada Desain Perpustakaan Pesantren, DIMENSI Journal of Architecture and Build Environment, Vol. 36, No. 2.
Samuel, W. 2011. Performance and Permeability: An Investigation of the Mashrabiya for use within the Gibson Desert in Australia (pp. 42-57). Master Thesis, School of Architecture and Design of Victoria University, Wellington, New Zealand.

Sherif. A, Sabry, H., Rakha, T. 2012. External perforated Solar Screens for daylighting in residential desert buildings: Identification of minimum perforation percentages. Journal of Solar Energy, 86(12), 1929-1940.

https://www.archdaily.com/510226/light-mattersMashrabiyas-translating-tradition-into-dynamicfacades, 19 Mei 2019 